http://jmscr.igmpublication.org/home/ ISSN (e)-2347-176x ISSN (p) 2455-0450

crossref DOI: https://dx.doi.org/10.18535/jmscr/v8i2.121

Journal Of Medical Science And Clinical Research

\title{
Retrospective Analytical Study on Spectrum of Antenatal Rupture Uterus Cases Presented in a Tertiary Care Centre
}

\author{
Authors \\ Dr Pratyaksha Raina, Dr Nupur Nandi, Dr Rehana Nazam
}

\begin{abstract}
Introduction: Rupture uterus is defined as a full thickness separation of uterus wall and overlying serosa. Various causes attributed are scarred uterus following LSCS, obstructed labor or traumatic. Rupture uterus is a life threatening obstetrics emergency with high maternal and perinatal mortality.

Aim and Objectives aim of study was to critically analyzing all patients presented with rupture uterus and to assess its preventable risk factors, exact presentation and outcome of mother and baby. This was achieved by recording following parameters: To record various presentations of rupture uterus cases, to identify the conditions which could have led to rupture uterus and to study the consequences of rupture uterus for both the mother and the baby.

Methodology: It is a retrospective observational study done between May 2018 - May 2019 in TMMC \& RC, Moradabad, Uttar Pradesh. All patients presented with rupture uterus were taken.A detailed history to evaluate various risk factors, examination, its management and intraoperative findings were studied to establish the cause in each case.

Result: Total 17 cases reported with rupture uterus during analysis time period whereas total number of delivery cases were 3336.

My retrospective study confirms important risk factors for uterine rupture which included prior $C$-section, multiparty, obstructed labour, inappropriate trial\& injudicious use of oxytocics.

The consequence of uterine rupture depend on duration of time that has elapsed from occurrence of rupture until definitive management from supportive \& resuscitative measures should be undertaken to prevent consequences, the type of surgical intervention depend upon type, location and extent of uterine rupture.Out of total 17 women who experienced rupture uterus-1 (5.8\%) died.

Conclusion: By noticing the strong association of non-utilisation of ANC with rupture uterus cases establishing 100 percent institutional delivery, improving the care and monitoring during labour at each level of health care system and coordination between health care facilities should be a priority for reducing future uterus rupture cases. Also safe prevention of the primary caesarean delivery should be practised to reduce the incidence of rupture uterus.
\end{abstract}

\section{Background}

Complete uterine rupture a rare complication of the peripartum.1 It is often related with a devastating consequence for mother and almost always for the infant. ${ }^{2}$ Uterine rupture is the consequence of obstructed labour, unusual delays in obstetric treatment and irrational uterotonic use. $^{3}$

It is predicted that the occurrence of uterine rupture will increase due to increasing rates of caesarean section around the world. ${ }^{4}$ The estimated incidence of rupture uterus among 
females who attempted vaginal delivery after cesarean section is approximately thirty five cases (32-37) / 10,000 deliveries ${ }^{5}$, whereas it is much lower among women who attempt childbirth vaginally without prior caesarean delivery and is estimated at approximately 0.6 cases $(0.5-0.7)$ per 10,000 deliveries. ${ }^{6}$

Definitely, the utmost main factor when assessing the likelihood of antenatal rupture uterus is whether or not the uterus has a prior scar. ${ }^{7}$

An unscarred uterus rupture is less common and resulted typically from trauma or mismanaged labour.

Often clinical presentation8 of ruptured uterus is dramatic which includes: symptoms like features of shock, discomfort, sudden loss of contractions with previous intense contractions, bleeding per vaginum and intrauterine fetal deaths which has low sensitivity.

Morbidities resulting from uterine rupture include extreme haemorrhage, pain, hysterectomy, post haemorrhagic anaemia, fistula formation like vesico-vaginal, increased risk for infection, death and more chances of rupture uterus in future conceptions. 7

Reported mortality rate due to rupture is between 1-13 percent and perinatal mortality between 7492 percent. $^{9}$

Due to severe concerns of rupture uterus, prevention is of utmost importance. Hence our retrospective study will concentrate on finding the factors leading to rupture, clinical presentation and consequences of rupture uterus to the mother and also the baby.

\section{Materials and Methods}

The aim of my study was to critically analyzing all patients presented with rupture uterus and to assess its preventable risk factors, exact presentation and outcome of mother and baby. This was achieved by recording following parameters:

1) To record various presentations of rupture uterus cases.
2) To identify the conditions which could have led to rupture uterus.

3) To study the consequences of rupture uterus for both the mother and the baby.

A hospital based retrospective analytical study of antenatal rupture uterus cases admitted to Department of Obstetrics and Gynecology TMMC \& RC, Moradabad UP during span of 1 year period from $1^{\text {st }}$ May2018- 30 ${ }^{\text {th }}$ April 2019 was evaluated.

\section{Methodology}

After availing the consent from institutional ethical committee we proceeded with our study. Sample included all antenatal rupture uterus cases presented during study period.

Multiple risk factors attributed to rupture uterus were divided into two categories: maternal characteristics and obstetric factors.

Maternal characteristics include-age, parity, number of prenatal visits for the indexed delivery, any medical co-morbid condition like anaemia, eclampsia/ preeclampsia, CVS or renal pathologies, chronic pulmonary disease, HIV/ AIDS, GDM etc. These datas were collected from patients, their attendants and from antenatal record cards.

The following obstetric factors were obtained like prior caesarean delivery, labour details-induced or spontaneous, inducing and augmentation agents, weather labour was managed by quacks or at home by untrained person, any congenital malformation of uterus.

Clinical presentations were assessed to detect women came in haemodynamic shock, moderate to severe anaemia (haemoglobin less than $8 \mathrm{gm} / \mathrm{dl}$ ), renal failure or multiorgan failure, obstructed labour.

Babies were grouped in two categories dead and live at time of presentation. Birth weight were also recorded.

Management of these cases were analysed on the parameters of need for blood or blood product transfusion, operational measures like repair or 
hysterectomy and post-operative events and need for Intensive care unit and mortality (if any).

\section{Statistical Analysis}

Descriptive statistics was performed by calculating mean and standard deviation for the continuous variables.

The software used was SPSS Version 25.0 software.

\section{Results and Analysis}

Total 17 cases reported with rupture uterus during analysis time period whereas total number of delivery cases were 3336 .

The mean age of females in our study was $30+/-3$. $02(25-38 \mathrm{yr})$. Mean parity in our study was 3 with a maximum of 6 births.

Table 1 illustrates various maternal demographic factors associated in rupture uterus cases.

\begin{tabular}{|l|c|c|c|}
\hline $\begin{array}{l}\text { Maternal Demographic } \\
\text { Factors }\end{array}$ & $\begin{array}{c}\text { Rupture uterus } \\
\mathbf{N = 1 7}\end{array}$ & Percentage \\
\hline AGE (YEARS) & & & \\
\hline & $20-35$ & 15 & 88.2 \\
\hline & $>35$ & 2 & 11.8 \\
\hline & & & \\
\hline PARITY & PRIMI & 2 & 11.8 \\
\hline & $2-4$ & 11 & 64.7 \\
\hline & $>-5$ & 4 & 23.5 \\
\hline
\end{tabular}

Result showed commonest presentation age group was between 20-35 years age. Although in higher age $>35$ years frequency of rupture was more but results is not statistically significant as less number of cases presented in this group. Also Grand multiparty patients has more frequency of rupture uterus but the results was not statistically significant.

Table 2: Relation of Not availing ANC and moderate to severe anemia on rupture uterus

\begin{tabular}{|l|c|c|c|c|c|c|}
\hline & & $\begin{array}{c}\text { Rupture } \\
\text { Uterus } \\
\text { N=17 }\end{array}$ & Percentage & $\begin{array}{c}\text { Total deliveries } \\
\text { N=3336 }\end{array}$ & Percentage & p-value \\
\hline PRENATAL VISITS & NONE & 5 & 29.41 & 334 & 10.01 \\
\hline & $1-4$ & 10 & 58.8 & 2535 & 75.98 & 0.030 \\
\hline & $>4$ & 2 & 11.8 & 466 & 13.96 & \\
\hline $\begin{array}{l}\text { ANEMIA } \\
\text { (HB<8mg/dl) }\end{array}$ & & 12 & 70.58 & 667 & 19.99 & $<0.001^{*}$ \\
\hline
\end{tabular}

Significant increase $(\mathrm{p}=0.030)$ in rupture uterus were noted in cases who were left out of antenatal care. Moderate to severe degree of anemia also found significantly $(\mathrm{p}=<0.001 \%)$ in our study subjects. No other comorbidity found significant in our study.

Table 3 Classifies various obstetrical factors that that can lead to rupture uterus.

\begin{tabular}{|l|c|c|c|c|c|}
\hline $\begin{array}{l}\text { OBSTETRICAL } \\
\text { FACTORS }\end{array}$ & $\begin{array}{c}\text { Rupture } \\
\text { uterus }\end{array}$ & Percentage & $\begin{array}{c}\text { Out of total } \\
\text { deliveries No } \\
\text { Rupture }\end{array}$ & Percentage & p-value \\
\hline $\begin{array}{l}\text { OXYTOCICS USED } \\
\text { FOR INDUCTION }\end{array}$ & 4 & 23.52 & 1896 & 56.83 & $<0.001^{*}$ \\
\hline PRIOR CESAREAN & 10 & 58.8 & 326 & 9.77 & $0.001^{*}$ \\
\hline & & & & & \\
\hline $\begin{array}{l}\text { OBSTRUCTED } \\
\text { LABOUR }\end{array}$ & 3 & $17.64 \%$ & 36 & 1.07 & $<0.001^{*}$ \\
\hline MALPRESENTATION & 2 & $11.76 \%$ & & - & - \\
\hline
\end{tabular}

Results showed prior caesarean section, improper use of oxytocics and obstructed labour was significantly related to rupture uterus. 
Table 4: Fetal outcome in antenatal rupture uterus cases

\begin{tabular}{|l|c|c|c|}
\hline & & NUMBER & PERCENTAGE \\
\hline BIRTH WEIGHT $(\mathrm{gm})$ & $<2000$ & 2 & $11.7 \%$ \\
\hline & $>2000$ & 15 & $88.3 \%$ \\
\hline & & & \\
\hline
\end{tabular}

\section{FETAL OUTCOME}

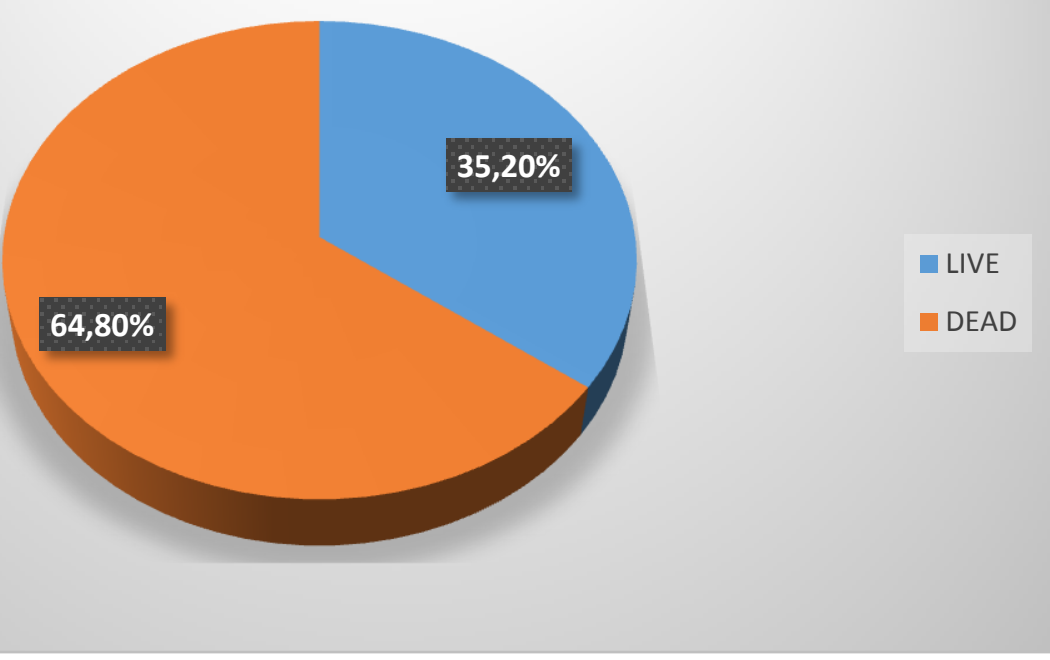

Significant number 11 cases $(64.8 \%)$ had already presented with dead babies. Although 6 cases $(35.2 \%)$ babies could be saved as they presented earlier where immediate surgery was performed. Most of the babies (88.3\%) born in rupture uterus were more than $2 \mathrm{~kg}$ in birth weight.

Table 5: Operative outcome in antenatal rupture uterus cases

\begin{tabular}{|l|c|c|}
\hline OUTCOME & NO OF CASES & PERCENTAGE (\%) \\
\hline OBSTETRIC & 4 & 23.52 \\
HYSTERECTOMY & & \\
\hline REPAIR & 13 & 76.47 \\
\hline
\end{tabular}

Repair of uterus was possible in most cases us with profound intraperitoneal contamination, $76.47 \%$, although obstetrics hysterectomy was rugged tear edge and necrotic tissue.

required for $23.52 \%$ cases as they presented late to

Table 6: Consequences of antenatal rupture uterus

\begin{tabular}{|l|c|c|}
\hline & No of Patients & Percentage (\%) \\
\hline SHOCK & 11 & 64.70 \\
\hline SEVERE ANEMIA & 9 & 52.94 \\
\hline SEPSIS & 3 & 17.64 \\
\hline & & \\
\hline ICU STAY & & 17.64 \\
\hline 1-2days & 3 & 82.35 \\
\hline$>2$ days & 14 & \\
\hline & & 29.4 \\
\hline BLOOD TRANSFUSION & & 70.58 \\
\hline 1-2 units & 5 & 5.88 \\
\hline$>2$ units & 12 & \\
\hline MORTALITY & 1 & \\
\hline
\end{tabular}


Significant number of patients $(64.70 \%)$ presented in shock, all were anemic of which $52.94 \%$ were severely anemic, all cases needed ICU admission out of which $82.35 \%$ required ICU support for more than 48 hours, $17.64 \%$ had sepsis.

Out of total 17 women who experienced rupture uterus-1(5.8\%) died. Nearly this death was due to rupture uterus or the consequences of rupture uterus (i.e. irreversible shock).

\section{Discussion}

Rupture uterus in generally occurs due to neglected labor, poor utilisation of resources resulting in obstructed labor, difficult or improper obstetric manipulations or frequently in high-risk patients such as- multiparity or women with previous cäsarean delivery, pregnancy with comorbidities.

The 25-35 year age group which was close to the research by Mahabuba et $\mathrm{al}^{10}$ (2012) was most frequently seen in our study of rupture uterus. 67.5 per cent of uterine rupture occurred in multipara (para 2 and above), while Malik HS ${ }^{11}$ (2006) found 42.7 per cent. Majority of patients had been unbooked and had less frequent antenatal checkups.

Sweeten et $\mathrm{al}^{12}(2005)$ stated that weakening and stretching of uterine muscle fibers during labor may weaken the uterus, especially with aging and repeated childbearing, this also predisposes to malpresentation and unstable lie, a major risk factor for ruptured uterus.

Previous caesarean accounted for about 58.8 percent of cases. This is a higher in comparison with the Sahu $\mathrm{L}^{13}$ (2006) study in which a previous scar involved 50 per cent of ruptures.

Our study showed higher rate of intrauterine fetal loss $(64.8 \%)$ following a rupture which was similar to Ofir et al i.e $62.3 \%$.

In our study, uterine rupture was associated with oxytocin use by improper hand in a significant number of patients (23.5 percent), similar to the study of Al Sakka et $\mathrm{al}^{14}$ (2009) which was 24.8 percent.
Our rate of patients requiring obstetric hysterectomy was $20.6 \%$ following complete uterine rupture and was close to previously found by Charach et $\mathrm{al}^{15}(2013)$ as 34 hysterectomies $(20.7 \%)$ in 164 complete uterine ruptures patients.

Ofir et al in 2003, who reported $26.2 \%$ out of 42 complete ruptures which were accompanied by obstetric hysterectomies. In our research, association of limited hysterectomy with primigravida may reflect the general attitude of patients and their relatives in this community to maintain fertility.

Care delay is a major factor leading to maternal ill-health and death resulting from rupture uterus. Thaddeus and Maine ${ }^{16}(1994)$ found that the majority of maternal deaths and maternal morbidity occur when women who are pregnant do not seek prompt emergency obstetric treatment. In this sample, mortality was $5.88 \%$ comparable to their study which was $8.28 \%$. Maternal mortality secondary to uterine rupture was found to be lower in this study than in the Angolan study (13.6 percent) in 2002 and in Adigrat (11.1 percent) ${ }^{17,18}$ in 2010 The possible explanation for this could be earlier hospitalization of mothers, early diagnosis of uterine rupture, adequate patient resuscitation, availability of blood transfusion, absence of delay between diagnosis and definitive management and involvement of a skilled surgeon has the effect of reducing maternal death following uterine rupture.

\section{Limitation}

The drawback of this research is that it reveals aspects of rupture uterus related to a particular geographic area in Moradabad, Uttar Pradesh as it is a single centre study, so it cannot be extrapolated to the entire Indian population. Since our hospital is also a tertiary centre it receives many referral cases from adjacent areas, so the rupture rate is likely to be higher.

\section{Conclusion}

By noticing the strong association of nonutilisation of ANC with rupture uterus cases 
establishing 100 percent institutional delivery, improving the care and monitoring during labour at each level of health care system and coordination between health care facilities should be a priority for reducing future uterus rupture cases. In addition, efforts to improve approaches at level of fertility attitude such as addressing unmet family planning needs and improving access and participation in prenatal care may help to reduce women's risk of rupture uterus in such settings.

Early diagnosis and reporting of rupture uterus may decrease near miss cases and mortality. Also safe prevention of the primary caesarean delivery should be practised to reduce the incidence of rupture uterus.

\section{References}

1. Ofir K, Sheiner E, Levy A, Katz M, Mazor M. Uterine rupture: risk factors and pregnancy outcome. Am J Obstet Gynecol 2003; 189:1042-6.

2. Al-Zirqi I, Daltveit AK, Forsén L, StrayPedersen B, Vangen S. Risk factors for complete uterine rupture. Am J Obstet Gynecol 2017; 216(2):165.e1-165.e8

3. Menihan CA.Uterine rupture in women attempting vaginal birth following previous caesarean birth.Journal of perinatology 198; 18:440-443.

4. Ravasia DJ,Wood SL \& Pollard JK. Uterine rupture during induced trial of labour among women withprevious cesarean delivery. American Jourrnal of Obstetrics and Gynaecology 2000; 183:1176-79

5. Vandenberghe G, Bloemenkamp $\mathrm{K}$, Berlage S, Colmorn L, Deneux-tharaux C, Gissler M. The International Network of Obstetric Survey Systems study of Uterinerupture: a descriptive multi-country population-based study. 2018;1-12

6. Guise J-M, Denman MA, Emeis C, Marshall N, Walker $\mathrm{M}, \mathrm{Fu} \mathrm{R}$, et al. Vaginal birth after cesarean: new insights on maternal and neonatal outcomes. Obstet Gynecol. United States; 2010 Jun; 115(6):1267-78.

7. Smith JG, Mertz HL, Merrill DC. Identifying risk factors for uterinerupture. Clin Perinatol 2008; 35:85-99.

8. Guiliano M, Closset E, Therby D, Le Goueff F, Deruelle P, Subtil D. Signs, symptoms and complications of complete and partial uterine ruptures during pregnancy and delivery. Eur $\mathbf{J}$ Obstet Gynecol Reprod Biol. Elsevier Ireland Ltd; 2014; 179:130-4.

9. Motomura K, Ganchimeg T, Nagata C, Ota E, Vogel JP, Betran AP, et al.Incidence and outcomes of uterine rupture among women with priorcaesarean section: WHO multicountry survey on maternal and newbornhealth. Sci Rep. 2017; 7:44093.

10. Mahbuba, Alam IP. Uterine rupture: Experience of 30 cases at Faridpur Medical College Hospital. Faridpur Med Coll J. 2012;7(2):79-81

11. Malik HS. Frequency, predisposing factors and fetomaternal outcome in uterine rupture. J Coll Physicians Surg Pak. 2006; 16:472-75.

12. Sweeten KM, GravesWK, Adelusi B. Spontaneous rupture of unscarred uterus. Am J Gynecol Obstet 1996;52:37-42.

13. Sahu L. A 10 year analysis of uterine rupture at a teaching institution. J Obstet Gynaecol India. 2006;56(6):502-06

14. Al Sakka M, Dawdah W, Al Hassan S. Case series of uterine rupture and subsequent pregnancy outcome. Int $\mathbf{J}$ Fertil1999;44:293-300.

15. Charach R, Sheiner E. Risk factors for peripartum hysterectomy following uterine rupture.The $\mathrm{J}$ Maternal Fetal Neonatal Medicine 2013; 26:12,1196-1200.

16. Thaddeus S, Maine D. Too far to walk: maternal mortality in context. Soc Sci Med. 1994;38:1091-1110. 
17. Gessessew A, Melese MM. Ruptured uterus-eight year retrospective analysis of causes and management outcome in Adigrat Hospital, Tigray Region, Ethiopia. Ethiop J Health Dev. 2002; 16(3):241-245.9792

18. Strand R, Tumba P, Niekowal J, Bergström S. Audit of cases with uterine rupture: a process indicator of quality of obstetric care in Angola. Afr J Reprod Health. 2010;14(2):55-62. 